\title{
Chapter 2 \\ Learn to Lead: Developing Curricula that Foster Climate Change Leaders
}

\author{
David Rhodes and Margaret Wang
}

\subsection{Introduction}

Imagine a group of ninth-grade students on a class trip, walking around the neighborhood of their school. The school is called Al Taqwa, and it is located in Rahat, a predominantly Bedouin city in the Negev desert of southern Israel. As the students explore the neighborhood, their assignment is to pay attention to any environmental problems they notice and take pictures of evidence related to those problems. Some students smell the toxic scent of burning plastic and they notice smoke rising from a pile of trash near the street. They snap several photographs before continuing on.

After returning from the trip, the teacher facilitates a discussion that engages the students in analysing the causes of the problems they observed. In the example of the burning garbage, the students explore how they might personally contribute to the problem by purchasing food and other items with plastic packaging. Then, they expand their analysis to consider the functions of the local and national government in managing waste. Questions are also raised with regard to the role of culture, highlighting the fact that burning waste was a common practice in Bedouin society with a history that extends back to a time when all the waste was organic. As the web of cause and effect grows increasingly complex, the class begins to incorporate causal diagrams to organize the information, and they start to construct maps of the different stakeholders involved.

In this course, the goal is to enable students to conceptualize and help address climate change problems in the region - problems associated with heat waves, droughts, dust storms, soil degradation, changing precipitation patterns and dryland water scarcity. The teachers, Fareed Mahameed and Samah Matany, are incorporating our high school Climate Change Leadership curriculum to equip and motivate students to affect change.

D. Rhodes $\cdot$ M. Wang $(\bowtie)$

Harvard Graduate School of Education, Cambridge, MA, USA 
The Climate Change Leadership curriculum is designed to integrate disciplinary concepts and process-based skills associated with defining problems, gathering evidence, generating solutions, synthesizing the possibilities for action, drawing conclusions with regard to the best way forward, communicating the results of the process and taking action. Throughout the curriculum, there are opportunities for students to practice empathy, systems-thinking, media literacy, and collaboration as they engage in projects connected to climate change. Clear standards, units, and lesson plans combined with an accompanying project-based assessment open possibilities for teachers to integrate the curriculum in a wide variety of ways.

We recognize that, in order for a curriculum to be effective, it needs to be accompanied by a strong implementation plan, and we are currently working with educators like Fareed to develop these plans for a variety of contexts. Ultimately, this approach to innovation in education is operating from a professional perspective that focuses on supporting the development of the capacity of teachers and school leaders to affect change (Reimers 2020). If we can build a network of teachers and school leaders interested in implementing the Climate Change Leadership curriculum and we can identify the customized support necessary for successful implementation, then the participating teachers will be able to enable climate change leaders in the new generation. We specifically focus on the development of a particular curriculum and its implementation because, in the context of Israel, there have been 17 reform initiatives in the past 30 years. If the curriculum were connected to a large scale reform, it could be more likely for it to be implemented in schools only so long as the initiative lasts, undermining the potential for longer-term integration of the curriculum.

In the first part of this chapter, we identify the problems in secondary school climate change curricula, particularly in Jordan, Israel, and Palestine. Then, we analyze the role of tertiary institutions through their relevant climate change pedagogical practices. Finally, we summarize the effective secondary education climate change resources that inform our curriculum. In the second part of the chapter, we present a Climate Change Leadership curriculum, highlighting how it integrates problem-solving frameworks from across disciplines to inspire inquiry and thoughtful action. We then describe our proposed standards to justify the pedagogical principles that are the basis of our curriculum. Lastly, we elaborate on our context-specific approach to the development of implementation plans to help schools successfully incorporate the curriculum.

We created this curriculum in collaboration with the Arava Institute, a tertiary education program in southern Israel that brings together Israeli, Palestinian, Jordanian and international students from outside the region to engage in multidisciplinary environmental studies, encompassing natural and social sciences as well as research into cross-border environmental issues. Thus, this curriculum was contextualized for Israel, Palestine, and Jordan, and we sought to learn from the work of the Arava Institute at the higher education level as we designed the curriculum for secondary schools in the region. While the regional focus has guided choices related to some of the curricular content, it is important to note that school leaders or teachers in diverse contexts could use the curriculum as well. Evidence that our 
project is not specific to the regional context can be seen in the success of EcoSchools - a global Education for Sustainable Development program with an approach to climate change education that aligns with core aspects of our curriculum (Andreou 2020). Ultimately, our goal is to help shift the conversation of climate change curricula away from how we teach climate change to how we can foster environmental leaders within younger generations.

\subsection{Analysis of Climate Change Curricula}

\subsubsection{The Problem with Climate Change Curricula in Israel, Jordan, and Palestine}

In Jordan, Palestine, and Israel, the governments have acknowledged the need for enhanced climate change education due to the region's semi-arid climate. More specifically, climate projections for the region include a rise of $3{ }^{\circ} \mathrm{C}\left(4^{\circ} \mathrm{C}\right.$ in Jordan), $10-30 \%$ decrease in precipitation (60\% for Jordan), seawater level rise of $10 \mathrm{~mm}$ leading to land loss, and an increase in extreme weather events including floods, droughts, and heat waves (EcoPeace Middle East 2019). These environmental fluctuations threaten food, energy, and national security. The impacts of climate change are further amplified by the region's influx of refugees and inter-state conflicts.

In this particular region, we chose to focus on a formal education initiative due to the sheer number of students in secondary schools. This may not be the case in many other regions as explored in Chap. 4, Haiti, and Chap. 5, Pakistan. As such, curriculum can be a powerful tool in implementing change in the formal education space and thus, affecting a large student population. In Israel, the secondary school net enrollment rate is around 98\% with around 820,000 students in the formal secondary system; in Jordan, the rate is $80.86 \%$ with around 790,000 students; in Palestine, the rate is $50.86 \%$ with around 750,000 students (UNESCO Institute of Statistics 2020).

Furthermore, there is already some sort of precedence of teaching about climate change within the formal education system. In the Jordanian high school curriculum, "Earth Sciences and Environment" is a separate subject studied by most public high school students that combines knowledge, skills, and behavioral domains. The curriculum also teaches students how to collect environmental information in their community and integrate it into civic action campaigns for awareness and advocacy. However, while the textbooks give instructions regarding how to apply environmental literacy to informed action, teachers and students do not necessarily have the knowledge and skills to conduct these projects (Al-Newashi 2002, p. 48). The formal high school system in Palestine faces comparable issues. Palestine also has environmental education as a mandatory subject between seventh and tenth grade. Nevertheless, an in-depth analysis of their main environmental education topic "The Science of Health and the Environment" reveals that while the curriculum addresses 
awareness and investigative skills, it is lacking in building major ecological concepts and applying their knowledge through positive environmental actions (Karama 2016, p. 14-17).

In contrast to mandatory environmental education in Palestine, in the Israeli high school system, education related to the environment is not compulsory and is only offered to students who major in "Environmental Sciences" or "Earth and Environmental Sciences." The "Environmental Sciences" curriculum has not been significantly updated since 1983 and it is mostly focused on students studying ecology. While students do have the option of selecting environmental ethics or environmental planning and management as a study unit, this constitutes a small population (Sagy and Tal 2015, p. 69). On the other hand, the "Earth and Environmental Sciences" curriculum is more aligned with climate change education as it focuses on "developing environmental insight" through systems-thinking (Sagy and Tal 2015, p. 70). However, since it is a new course, few students are exposed to this style of environmental education. In total, less than $10 \%$ of Israeli high school pupils are exposed to environmental education (Sagy and Tal 2015, p. 71). Since 2004, there have been initiatives spearheaded by the Ministry of Education and the Ministry of Environmental Protection to certify "Green Schools" based on a review of environmental practices of the school and environmental education curriculum. However, these initiatives fall short because there is no ongoing evaluation after the certificate is awarded to ensure that the school continues to perform to the relevant standards (Tal 2020).

Outside of the formal curriculum, there have been initiatives by various schools to transform the way climate change is being taught in the region. This is derived from a larger global movement through the United Nations Educational, Scientific, and Cultural Organization (UNESCO). This organization has provided climate change educational resources that clearly show education's role in mitigating climate change: enabling the youth to take collective action. For example, in UNESCO's course for secondary school teachers on climate change education called Climate Change in the Classroom, there is an emphasis on "motivating action through local learning" and "motivating learners through real life experience" (Selby and Kagawa 2013, p. 8). UNESCO has worked with the One UN Climate Change Learning Partnership (UN CC: Learn 2013) to directly disseminate curricular resources embodying these ideals.

On a global scale, climate change education is moving towards project-based learning, which is a pedagogical practice where students engage with an authentic problem or question. Through inquiry and reflection, they ultimately create a public product as a summation of their investigation. Similar approaches can be seen in regional initiatives such as Youth Xchange, ASPnet, and South Eastern Mediterranean Environment Project (SEMEP). Youth Xchange is a collaborative initiative of UNESCO and the United Nations Environment Programme that has designed materials to enable educators to teach sustainable lifestyles throughout the Middle East, including schools in Jordan (UNESCO and United Nations Environment Programme 2011). Similarly, ASPnet is dedicated to enabling schools to engage in climate change education that includes multi-disciplinary, collaborative projects (UNESCO 
Associated Schools Network n.d.). Resources include guidelines to build climate change education networks within schools and materials designed to facilitate climate change education across subject areas. Lastly, the South Eastern Mediterranean Environment Project (SEMEP) programs focused on teaching students to apply scientific methodology to address specific issues in their local contexts (Cyprus Ministry of Education and Culture 2012). For example, in Israel, Palestine, and Jordan, secondary school projects were developed related to water filtration and conservation. In Jordan and Palestine, students were involved in other SEMEP initiatives, including expanding green spaces to combat desertification, and exploring questions of ethics and global warming (Cyprus Ministry of Education and Culture 2012).

Through a review of the formal high school curricula in Israel, Jordan, and Palestine, there is clearly a need for updated curricula related to climate change combined with sufficient educator capacity to deliver the curricula. One way forward might be to adopt project-based initiatives in the region, inspired by UNESCO, to guide such curricula as these initiatives can help students learn about climate change and apply their knowledge in the context of local collaborative projects. In parallel with these initiatives, there would also be a need for substantive professional development for teachers to ensure that they have the skills and confidence to teach in this way. While this shift in climate change curricula and teacher training could be impactful, the impact would be limited by the fact that project-based initiatives are less attentive to ensuring that students come away with a deep understanding of frameworks for informed actions outside of the context of the curriculum and their particular projects. This undermines the ability of students to transfer their understanding and limits their ability to engage with the multi-faceted dimension of climate change outside of the context of the course. Therefore, in order to teach students how to translate their knowledge into sustained civic engagement, it is essential that the students not only engage in projects within their communities, but that they also deepen their understanding of the process-based underpinnings of informed civic action.

\subsubsection{Learning from Tertiary Level Climate Change Pedagogy in the Region}

The role of tertiary institutions extends beyond educating young adults - in the context of climate change education, they can be a source of knowledge for content and pedagogical practices. As such, we turned to the tertiary institutions in the region to analyze effective climate change curricula. For example, at the Technion in Israel, Daniel Orenstein teaches a course on environmental policy in which students develop their understanding of environmental policy analysis through the study and application of ideas from the work of Eugene Bardach's (2011) A Practical Guide for Policy Analysis: The Eightfold Path to More Effective Problem 
Solving (The Eightfold Path) and Steven Cohen's (2014) Understanding Environmental Policy. The students also engage in environmental projects in collaboration with local NGOs. In an interview, Orenstein shared the underlying rationale for the structure of his course as follows:

The [project] component is due to the desire to work closely with stakeholders to suggest real and implementable solutions to environmental challenges with local urgency, and to have a "built-in" group of individuals and organizations who are interested in the students' results. The [policy analysis] component is because I think Cohen's framework helps students build a very strong and interdisciplinary foundation and understanding of the given environmental challenge, but lacks operational steps to define policy alternatives and potential solutions, while the Bardach framework is void of depth of analysis of the given challenges, but provides a very well-developed framework for problem-solving. Together they compensate for each others' weaknesses (Orenstein, D. (2019, December). Email with authors).

In the Arava Institute, our partner tertiary institution, the Environmental Leadership seminar provides two tracks that "highlight the interplay between individual action and large scale institutional change as two important and complementary tactics for finding real solutions to today's environmental crisis" (Haber 2019, p. 1). The Sustainable Living Track involves exploration of a topic along with a hands-on project on campus with a facilitator and mentorship. The Environmental Diplomacy and Entrepreneurship Track includes activism and community organization through an international non-profit called WeSea as well as collaboration with business mentors. Similar to the UNESCO initiatives in secondary schools throughout the region, there is a focus on inquiry and experiential learning. However, in these courses, there is an emphasis on the assessment of the process alongside the public product in order to develop leadership skills and problem-solving strategies.

Thus, at the tertiary level, there are courses that enhance the civic agency of students by cultivating a deeper grasp of the disciplinary content as well as understanding and implementation of the process of policy analysis. But this approach to education related to climate change is not accessible at the secondary level, and only the students who can access higher education and then gravitate towards classes on environmental policy are exposed to this pedagogy. This clearly indicates a need for institutions of higher education and secondary schools to develop strategies that would enhance the exchange of ideas in ways that would make effective climate change education accessible to all.

\subsubsection{Effective High School Climate Change Education Resources}

Lastly, we reviewed high school climate change education resources outside of the region that would help inform climate change curricula. 


\subsubsection{Paleontological Research Institution: The Teacher-Friendly Guide to Climate Change}

The scales involved in climate change research lie outside the range of human experience, spanning billions of years and involving the interactions of microscopic particles and waves (Zabel et al. 2017). The systems and scales associated with climate change are often embedded in different disciplines within and beyond the context of the sciences, including biology, chemistry, atmospheric science, oceanography, geology, environmental sciences, etc. (Ledley et al. 2017, p. 6). In the United States, the Next Generation Science Standards (NGSS) recognizes the inherent interdisciplinary nature of climate change by promoting "cross-cutting concepts." Yet, by focusing on scientific complexity, teachers and students would get inundated with content, which could perpetuate the notion that only specialists can truly understand the issues, and thus, only specialists can address climate change (GonzalezGaudiano and Meira-Cartea 2012, p. 15). The combination of these factors renders it difficult to make the relevant content accessible in a high school curriculum.

As a result, the Paleontological Research Institute (PRI) created The TeacherFriendly Guide to Climate Change (TFG) (Zabel et al. 2017) to address these obstacles by explicitly engaging with questions of cognitive bias and providing tools for systems thinking. With accessible and engaging language combined with models and images, the challenge of grappling with the systems and scales connected to climate change is demystified. Once the challenge is clear, the next step is to practice actually grappling with complex systems and models, and that can happen through the development of lessons and activities incorporated into a curriculum.

Overall, there are two ways in which the TFG mitigates the risk of conveying that only professionals can engage with the issue of climate change. First, it makes the essential foundation in science accessible without going into all of the details embedded in each discipline. Students can learn about the carbon cycle, for example, without learning the underlying biological processes associated with respiration. While the foundation in science is included in the TFG, there is also a recognition of the fact that this foundation itself can still feel overwhelming, especially in combination with the myriad risks associated with climate change. Thus, it is essential to engage with the psychological aspect of the challenge as well, and the TFG does just that, calling attention to the sort of big picture thinking that can help students assimilate information while maintaining a sense of motivation and hope.

\subsubsection{Climate Interactive}

Climate change involves multilayered systems with feedback loops and evolving dynamics. This presents a significant challenge to educators who seek to engage students in complex systems analysis and enable them to affect change (Ledley et al. 2017). In education, when real-life context is introduced through inquiry and experiential learning, systems thinking is often emphasized as a valuable processbased skill. Systems thinking can be defined as a practice for understanding 
complex and dynamic systems and can include modeling to help with decision making and implementation (Ledley et al. 2017, p. 6).

Climate Interactive is a think tank from Massachusetts Institute for Technology that directly tackles the complexities of systems thinking by providing video lesson resources and simulations to teach people system dynamics modeling in climate change issues. For example, through games like World Climate, students learn the complexity of climate change negotiations. World Climate is a simulation game, in which participants role-play as delegates to work together and create an international global agreement to combat climate change. Iterative drafts of the agreement are coupled with a real-time display of its effects, which are backed by robust scientific data. In an evaluation involving participant surveys and focus groups, $85 \%$ of participants increased their motivation to take action and begin the inquiry phase. Furthermore, the program taught major systems thinking insights (Climate Interactive 2019).

Climate Interactive has also released an online course called the Climate Leader which trains students in systems thinking to motivate global response to climate change. Topics such as areas of high leverage and feedback loops give students specific heuristic models to understand the effects of human activity on the environment and vice versa.

\subsubsection{Project Look Sharp: Media Literacy}

There is no agreed upon resource with the full body of knowledge related to the issue of climate change. While the vast majority of scientists (more than 97\%) agree that human action impacts the climate and anthropogenic $\mathrm{CO}_{2}$ is causing global warming, a skeptic could still point to the small number of scientists who deny that such a causal link exists (Zabel et al. 2017). Furthermore, the issue of climate change has social and political dimensions that add layers of complexity to the analysis of sources and credibility. Some individuals or groups may present information to serve an agenda that has nothing to do with the pursuit of knowledge or the wellbeing of society at large. The obstacle to understanding presented by the intentional manipulation of information is compounded by the fact that anyone can fall prey to misinformation or unconscious biases (or both). To mitigate these risks, it is essential for the consumer of information to have the skills to decode bias, analyze credibility, and identify important missing perspectives. This includes metacognitive reflection on one's own biases in order to approach questions with an open mind and seek to identify and fill blind spots. For educators, it can be a difficult process to facilitate the development of media literacy skills necessary to explore questions associated with climate change.

Project Look Sharp (n.d.), a media literacy institute at Ithaca College, has honed the process of constructivist media decoding (CMD) to address the need for students to build media literacy skills. The process of CMD is inquiry based, and the role of the teacher is to present rich media documents for the class to analyze. A rich media document is one that has layers of complexity that connect directly to media 
literacy goals while engaging with content relevant to the curriculum. The teacher can lead the decoding by asking questions that engage the students in deep analysis of content, bias, credibility, purpose, techniques, and impacts. Decoding also involves analysis of how the interpretations of the document can vary, illuminating the ways in which our personal biases can shape the way we interpret the world. It is important to note that the process of CMD should be incorporated into analysis of documents that teach content, but the purpose of the decoding of the media document is not to teach the content itself. In CMD, questions are not designed to lead students to the teacher's predetermined conclusions, but rather to build the skills of inquiry and analysis, empowering the students to engage with each other and the documents. When students share insights and raise important questions, they engage in the practice of drawing evidence-based conclusions. Ultimately, the students develop the skills of decoding and the habits of inquiry that they can apply in the context of any complex question in order to understand how to draw informed conclusions based on an analysis of evidence from diverse perspectives and sources.

\subsection{Climate Change Leadership Curriculum}

\subsubsection{Rationale of the Curriculum}

In our analysis of existing climate change curricula in Israel, Jordan, and Palestine, we identified a pressing need for a curriculum that not only provides the necessary foundation in the sciences, but also helps students understand how to interpret scientific information to draw their own informed conclusions; a curriculum that not only provides students with an experience of agency through a hands-on project, but that also ensures that they understand how to design a project with attention to complex power structures, interconnected systems, and the needs and interests of diverse stakeholders; a need for a curriculum that not only instills a sense of civic responsibility, but that also provides a deep understanding of how to fulfill that responsibility by setting clear goals and collaborating with others to affect change. In other words, there needs to be curricula that help the student internalize the process of creative problem-solving and informed action. Students should graduate from high school with the skills and inclinations to mitigate the risks of climate change. This cannot happen solely through the practice of science in the classroom, nor can it happen solely through service connected to a project in the school or community. While these experiences and the associated learning outcomes may be necessary, they do not add up to the capacity for thoughtful policy analysis, innovative design thinking, or practical understandings of how to engage across divides to transform the future by mitigating the risks of climate change.

As a result, we have created an example of what a climate change education could look like called The Climate Change Leadership Curriculum (see Appendix A). It is important to note that implementation of a project-based curriculum 
without educator and school leader capacity would be insufficient, as ascertained by the project-based Jordanian curriculum. The resources we are developing, including this curriculum, are therefore constantly in revision through feedback from educators and schools involved in implementation. Before elaborating on the implementation plan, we will explain the different components in our curriculum that are informed by the gaps identified in climate change education as well as inspired by tertiary institutions in the region and effective global secondary school resources mentioned earlier.

\subsubsection{Anchor Skills}

The anchor skills delineate what students need to be able to do in order to exercise leadership specifically in the context of climate change. We identified four overarching themes: empathy, systems thinking, media literacy, and collaboration. These anchor skills are embedded throughout the curriculum, and metacognitive reflection on their application helps to ensure that students gain the ability to transfer the skills to new contexts.

Based on the review of effective high school climate change curriculum, these anchor skills are standards that must be taught in alignment with the process-based skills that guide the student leaders, which will be discussed in the next section. For example, in order to define problems, students need empathy to be able to approach questions with humility and seek to understand diverse perspectives. In order to gather evidence, students need media literacy to understand how to assess the credibility of information and consider the ways in which bias can lead to blindspots that need to be filled by seeking out missing perspectives. In order to generate solutions, students need systems thinking to understand how complex systems can be impacted by affecting change in areas of high leverage. And in order to draw conclusions, students need to understand how changes to specific areas of high leverage can help to transform harmful dynamics, effectively and efficiently promoting positive change. Eventually, students need to understand how to collaborate and motivate groups to take action based on their conclusions and inspire others to do the same. Then, they need to maintain their curiosity as they iterate the process, taking into account the actual impacts of their actions.

\subsubsection{Process-Based Skills}

Whereas the anchor skills revolve around climate change leadership competencies, process-based skills outline what the students actually have to do to engage in effective problem-solving that leads to informed civic action and, additionally, what it means to do these steps effectively. The process-based skills are drawn from three essential resources: Bardach's (2011) Eightfold Path, Stanford Design School's design thinking process (Platner n.d.), and the National Council for the Social Studies' framework called College, Career, and Civic Life (C3) (2017). 
If a goal of education is to foster thoughtful and engaged citizens, then policy analysis would be essential. However, the skills of the policy analyst are not explicitly included in traditional high school curricula, leaving the concept of policy analysis vague or inaccessible. In the Eightfold Path, public policy professor Eugene Bardach (2011, xvi) demystifies the conceptual framework behind policy analysis by identifying eight fundamental steps of the process, which we summarize below:

1. Define the problem - What is the problem under investigation?

2. Gather evidence - What perspectives and data would be necessary to analyze the way forward?

3. Construct alternatives - What are possible paths forward based on the evidence?

4. Select criteria - How should the alternative paths be weighed relative to one another? On what basis?

5. Project the outcomes - What would be the outcomes of the different paths?

6. Confront tradeoffs - What are the pros and cons of the projected outcomes relative to the criteria?

7. Focus narrow deepen decide - What path forward makes the most sense following an analysis of the tradeoffs?

8. Tell your story - What are effective ways to communicate the results of this process to garner support for the conclusion?

Similarly, design thinking brings in another layer of how to creatively think through problems in the following steps as summarized below (Platner n.d.):

1. Empathize - What does the target population care about and need?

2. Define - Based on the needs and interests of the target population, how should the problem be framed?

3. Ideate - What is a broad range of possible ways forward to address the problem?

4. Prototype - How can a prototype be built to further explore the best way forward?

5. Test - How can ideas for revision of prototypes be gained through testing and feedback?

6. Revise.

Lastly, the C3 framework also outlines process-based skills that begin with teaching students how to design inquiries and ends with communicating conclusions to take informed actions. Although this inquiry-based framework uses disciplinary concepts limited to social studies, the format could easily integrate science disciplines.

1. Dimension 1: Developing Questions and Planning Inquiries

2. Dimension 2: Applying Disciplinary Tools and Concepts (Civics, Economics, Geography, and History)

3. Dimension 3: Evaluating Sources and Using Evidence

4. Dimension 4: Communicating Conclusions and Taking Informed Action (National Council for Social Studies 2017)

The process based skills in our curriculum are structured following the sequence of Eugene Bardach's (2011) Eightfold Path, and they integrate the ideas embedded 
in design thinking and the $\mathrm{C} 3$ framework. In addition, the accompanying project directions for students outline these process-based skills in sequential order. The benefit of making this process transparent to students is that they can learn how to apply skills of policy analysis, design thinking, and inquiry to multiple aspects of climate change and/or other issues, and they could engage in a self-directed iterative process. In other words, by including the following process-based skills, students are able to internalize effective problem-solving processes:

1. Defining problems: developing compelling questions that promote inquiry and crafting meaningful and actionable problem statements.

2. Gathering evidence: Determining the types of relevant sources, evaluating for credibility, and gathering information from these various and diverse sources.

3. Generating solutions: Synthesizing evidence to generate a wide range of ideas and creating externalized prototypes to communicate potential solutions and receive feedback.

4. Concluding: Applying selection criteria, assessing strengths and weaknesses of outcomes, and drawing conclusions on how to proceed.

5. Communicating and acting: Communicating the results and trade-offs and taking direct actions towards implementing the results of the analysis.

This draws upon evidence of the efficacy of an inquiry learning cycle that fosters the students' sense of responsibility and autonomy in the process of knowledge generation and cultivates the ability to apply knowledge to new context (Cairns 2010). In many ways, our project builds upon work being done in environmental education grounded in experiential learning theory. For example, the Enviroschools Programme in New Zealand incorporates a learning cycle that involves identifying a current situation, exploring alternatives, taking action, and reflecting on change (Eames and Mardon 2020).

\subsubsection{Disciplinary Tools and Concepts}

All of the above skills are directly relevant to mitigating the risks of climate change, and they must be taught and assessed in order for students to emerge with the capacities for climate change leadership. But they will only lead to an impact on climate change if they are also utilized to help students understand what climate change actually is. We integrated disciplinary tools and concepts into our curriculum because leadership cannot be taught in the absence of hard knowledge. In other words, science is necessary in climate change leadership. Instead of replacing the science behind climate change that is usually taught in isolation, our curriculum provides an example of what it would look like for students to have the space to apply scientific knowledge. Thus, teachers must facilitate students' acquisition of the foundational disciplinary tools and concepts to navigate questions related to climate science.

TFG (Zabel et al. 2017) distills these tools and concepts in a clear conceptual framework, identifying the bigger ideas in earth system sciences necessary in 
understanding climate change. This includes the parts in the Earth System, energy processes, human environmental interactions, physical and chemical principles, and maps and models. In collaboration with PRI, we have adapted disciplinary tools and concepts for the context of our Climate Change Leadership Curriculum to the following:

1. Climate: Explaining how life is influenced by the environment and describing physical and chemical principles that affect the Earth's systems.

2. Energy: Describing how the flow of energy drives the cycling of matter.

3. Model and Maps: Interpreting and creating models and maps to understand (deep) time and scale of space

4. Earth Systems: Explaining the multitude of systems Earth is composed of as well as the system Earth belongs to.

\subsubsection{Resources Guiding the Educator}

In this section, we outline the resources available to educators in our curriculum. Ultimately, the resources would need to be accompanied by high-quality, contextspecific professional development, and we outline our approach to PD in the following section on plans for implementation. By grounding the resources in clear standards, educators can readily identify the skills students need to develop and demonstrate throughout a climate change curriculum. To illustrate the product of this standards-based curriculum design, we have created an example of a 12-week curriculum resulting in a final student project. Anchor skills, process-based skills, and disciplinary tools and concepts are all integrated into each unit within the Climate Change Leadership Curriculum, emphasizing the importance of inquiry and experiential learning. As a result, each unit is based on at least one standard from each sub-section of skills:

Unit 1: Becoming Inquirers.

Unit 2: What is Climate? Why Does Climate Change?

Unit 3: Challenges to Understanding Climate Change.

Unit 4: Defining Problems to Solve in the Context of Climate Change.

Unit 5: Cognitive Biases and Logical Fallacies in Climate Change.

Unit 6: Gathering Evidence from Credible Sources.

Unit 7: Brainstorming Strategies to Address Climate Change.

Unit 8: Getting Feedback on Climate Change Strategies.

Unit 9: Creating a Criteria for Effective Climate Change Solutions.

Unit 10: Confronting Tradeoffs in Climate Change Policies.

Unit 11: Telling Your Story About Climate Change.

Unit 12: Taking Action in Addressing Climate Change.

In each unit, we provide a series of activities that guide teachers on how students could reach the standards. These activities are organized based on which essential question they address in the lesson so that teachers can understand the purpose 
whilst engaging in the activity and thus, modify it to meet the needs of their classroom. In Appendix A, we provide an overview of our activities.

The pedagogy incorporated in the activities is designed to reflect the skills and inclinations associated with the learning objectives. The teacher exposes students to ideas and sources and facilitates their ability to make meaning through individual and group analysis and reflection. If the teacher were to simply present the material, draw conclusions, and assign projects for the students, it would actually undermine the message that students should have agency in the process of learning and civic action. In fact, it would implicitly suggest that the voices of students do not matter. With that established, the teacher has an essential role to play when it comes to ensuring that there is a sense of accountability to the deeper mission of learning. The clarification of this mission is important to highlight the role of the teacher in terms of ensuring that the learning space is maintained and that students follow through with their work. While methods for ensuring accountability can vary, most methods generally include standard-based rubrics that are used to evaluate student work.

This is not to suggest that teachers cannot present information to students. On the contrary, teachers should use their understanding to help ensure that students can access information in a clear and engaging way. At times, the teacher may be uniquely suited to directly impart information, and oftentimes the teacher plays a role in curating information. But critical thinking on the part of the students should be encouraged at all times as students "decode" the messages of the teacher, and the teacher should model the skills and habits of inquiry and curiosity as an essential means of transferring those skills and habits to students. Furthermore, in the context of an issue as complex as climate change, there is a good chance that a teacher would be much more credible about some aspects of the issue than others, and as students pursue their own projects, the teacher plays the role of a coach and guide in the process. As the course progresses, students are provided opportunities to play these roles as well, supporting each other in the learning process as they develop skills of collaboration.

Lastly, we provide a student resource that serves as a project template, guiding the students through the process-based skills - essentially the process of creatively solving problems and taking informed action. This project template also serves as a resource for the educator as it provides an opportunity for students to practice the skills touched upon in the units through formative assessments related to a topic that they had agency and choice over (See Appendix B for an overview of the student project). Furthermore, it can be used as a summative assessment in the form of a meaningful capstone project. As a result, not only does it inform teaching throughout the curriculum, but it also allows for meaningful assessment of the process so that students can internalize the process of creative problem-solving and transfer it to other contexts throughout their life. 


\subsection{Implementation and Program Theory}

There are several aspects of the context for delivery that are essential for the curriculum to make an impact, of which the teacher is the most important. In particular, the teacher interested in implementing the curriculum would need to have the skills to deliver the lessons as well as an understanding of the content of each lesson. Together with other faculty and school leaders, they would also need to be able to assess contextual factors that would dictate the ways in which the curriculum could be adapted to align effectively with the particular priorities and constraints of the institution.

The current implementation plan involves seeking feedback from teachers to learn what sort of professional development they might need and how they might adapt the curriculum to their contexts. As we learn from teachers about those needs, we can work with them to create modified versions of the curriculum that would be suited for implementation under different circumstances with consideration for various constraints in terms of time and/or other resources. Ultimately, we will have a wider variety of options for both professional development and implementation that teachers and school leaders could review. With that established, it would still be important to further align both the professional development and the curriculum with the needs of a particular school or course.

In order to find schools and teachers who would be interested in implementing the curriculum and giving us feedback, we have been working closely with the Arava Institute to identify alumni who may be involved in secondary education. Through this process, we were introduced to Fareed Mahameed. Fareed works with the Hura Agricultural Sustainable Farm, a program in the Negev Desert designed to serve as a center for research, education, and training for primary, middle and high schools in the region with a focus on integrating experiential education to learn about nature and the environment. We spoke with Fareed about the Climate Change Leadership Curriculum, and he went on to establish a partnership between the Hura Agricultural Sustainable Farm and the Al Taqwa Secondary school in Rahat, Israel, where he would teach the curriculum in collaboration with high school teacher Samah Matany. With the partnership, we worked together to adapt the curriculum to meet the needs and constraints of the Al Taqwa school. We also scheduled regular times to speak with Fareed to offer support in his delivery of the curriculum and to solicit feedback regarding the experiences of the different stakeholders involved.

In addition to conversations with the teacher implementing the curriculum, we will also collect student work, assessments, and surveys in order to gain a more complete picture of the experiences and perspectives necessary to inform the way forward. Furthermore, surveys with questions linked to each of the standards for the curriculum will be administered at the start and end of the course to gain insight into the efficacy of the curriculum. In Al Taqwa, Fareed administered a survey to the students that tested basic knowledge and confidence about climate change linked to the disciplinary tools and concepts, process-based, and anchor standards. In addition, we had survey questions regarding their general attitude about climate change 
leadership. The survey results provide a baseline for us to be able to measure impact through a post-survey. It also provided insight into the population of students we were working with. For example, Fareed noted that most students did not believe that individual actions could lead to climate change mitigation, which allowed him to consider how he could use specific units in systems thinking to address this attitude.

As students engage in the course, they will also have opportunities to demonstrate their assimilation of ideas related to climate change and the process of policy analysis through collaborative projects, personal reflections, and written assessments. Student project proposals that extend beyond the contained structure of the class will be the key indicator of their ability to transfer the understandings acquired during the course to new contexts. Finally, feedback from alumni will be solicited to measure their motivation and ability to continue to engage with the issue of climate change.

\subsection{Conclusion}

It is not sufficient for climate change education to focus on knowledge acquisition, and, even when students have opportunities to apply knowledge to address realworld problems related to climate change, an essential objective of climate change education is still left unmet. In particular, students need to understand the complexities of each step of the processes associated with thoughtful civic engagement in order to be enabled to truly lead in mitigating climate change. As students develop their understanding of how to affect change within complex systems, the standards and assessments must be aligned to these process-oriented skills in addition to the content knowledge. Ultimately, as students realize their potential to integrate thinking and practice, they will be able to affect meaningful change.

While a curriculum can provide the pedagogical frameworks and lessons to foster climate change leaders, a curriculum alone does not lead to successful implementation. Change comes about when the context-specific needs and interests of diverse stakeholders are considered and training and support is customized for teachers involved in the delivery of the curriculum. As we continue to engage in this work, there is potential to build an expanding network of educators and schools dedicated to fostering climate change leaders. By changing the way climate change is being taught, we hope that several high school students will be inquiring and observing the various impacts of climate change within their community and then be equipped, motivated, and empowered to take actions just like the ninth graders in Rahat, Israel. 


\section{Appendices}

\section{Appendix A: Climate Change Leadership Curriculum}

This is a modified version of our curriculum with brief descriptions. The full curriculum can be accessed: https://climatechangeleadership.weebly.com/

Standards: Students will be able to....

\section{Anchor Skills}

\section{A. Empathy}

1. Communicate with people to understand why they do things, what their physical and emotional needs are, how they think about the world, and what is valuable to them.

2. Engage in constructive dialogue and public messaging connected to controversial issues, seeking to transform harmful dynamics and promote positive change.

\section{B. Systems Thinking}

1. Outline how actions can affect multiple stakeholders.

2. Identify causal webs of external and internal factors within and between systems.

\section{Media Literacy}

1. Critically analyze media in terms of origins, purpose, content, values and limitations.

2. Metacognitively reflect on personal biases and blind spots.

D. Collaboration

1. Work effectively with others through aligned goals.

\section{Disciplinary Tools and Concepts}

\section{A. Climate}

1. Explain how life, including human life, influences and is influenced by the environment

2. Describe physical and chemical principles that are unchanging and drive both gradual and rapid changes in the Earth system

B. Energy

1. Describe how the flow of energy drives the cycling of matter.

C. Models and Maps

1. Interpret and create models and maps to understand (deep) time and scale of space. 
D. Earth Systems

1. Explain the multitude of systems Earth is composed of as well as the system Step 1: Defining Problems

A. Develop compelling questions that promote inquiry around key disciplinary concepts and relevant, current issues.

B. Craft meaningful and actionable problem statements through the lens of the affected human population based on analysis and synthesis of diverse, relevant perspectives.

Step 2: Gathering Evidence

A. Determine the types of sources that will assist in understanding the problem and potential solutions.

B. Gather relevant information from various and diverse sources and evaluate for credibility.

Step 3: Generating Solutions

A. Synthesize evidence to generate a wide range of ideas to reach innovative solutions to a problem.

B. Create externalized prototypes to communicate potential solutions and receive feedback.

Step 4: Drawing Conclusions

A. Identify selection criteria and apply the criteria to different prototypes of potential solutions.

B. Synthesize the assessment of the relative strengths and weaknesses of different outcomes to draw conclusions about how to proceed.

Step 5: Communicating and Acting

A. Communicate the results of the process with relevant explanations and confront trade-offs.

B. Take direct action towards implementing the results of the analysis.

\section{Unit 1: Becoming Inquirers}

\section{Essential Questions}

- Why is inquiry important?

- What is inquiry and how does inquiry differ from advocacy?

- How do you develop skills required to engage in inquiry?

- How do you overcome common challenges when it comes to engaging in inquiry?

- What are the benefits of engaging in inquiry?

\section{Rationale}

In responding to the risks associated with climate change, it can be tempting to start with advocacy. We may want others to understand the dangers and feel 
inspired to join the effort to mitigate the risks. But this approach may overlook basic assumptions we bring to the table, thereby limiting our understanding of relevant perspectives that could inform our views on the goals and/or our understanding of the obstacles to progress. Unlike advocacy, inquiry starts from a place of curiosity. One way to think of the distinction between inquiry and advocacy is to consider different purposes for asking questions.

- Advocacy $=$ Teach, Lead, Persuade.

- Inquiry = Learn, Understand, Explore.

\section{Aligned Standards}

Anchor.A.1 Empathy: Communicate with people to profile why they do things, what their physical and emotional needs are, how they think about the world, and what is valuable to them.

Anchor.A.2 Engage in constructive dialogue connected to controversial issues, seeking to transform harmful dynamics and promote positive change.

1.A Develop compelling questions that promote inquiry around key disciplinary concepts and embedded enduring issues.

\section{Activities}

1. Take a Stand on a Spectrum - Teacher presents a statement such as "The point of engaging in discourse with people who hold opposing views is to persuade others to change their views," while students line up on a spectrum from "strongly agree" to "strongly disagree." Students share their rationale, which might influence others to change their opinions, which allows students to understand how engaging in inquiry impacts conversations and outcomes.

2. Gallery Walk - Teacher prepares the following prompt:

(a) "What are 'hot topics' that can lead to being blindsided by emotions?"

(b) "What do you look, sound like, feel like when you're blindsided by emotion?"

(c) "When you are blindsided by emotion, what are the impacts on the conversation?"

(d) "What can you do when you feel like you may be blindsided by emotion? What can you do when you see others in this situation?"

Students are divided into groups to write their own answers and rotate to observe other remarks and add additional comments.

3. Inquirer and Coach - Using the hot topics identified in the Gallery Walk Activity, teacher and a student will model a discussion while the student plays the role of an inquirer. Teacher takes a view in opposition to the student's firmly held beliefs. Other students can volunteer as coaches.

4. Take Space and Make Space - Teacher poses the question: "How likely are you to take space when you have an idea you want to communicate?" From class discussion, teacher establishes the purpose of inquiry and classroom norms. 


\section{Unit 2: What Is Climate? Why Does Climate Change?}

\section{Essential Questions}

- What are compelling questions about climate change?

- What is a compelling question and what is a supporting question?

- What is climate and how does it relate to energy?

- What are long term vs. short term natural causes of climate change in Earth's history?

\section{Rationale}

According to the College, Career, and Civic Life (C3) Framework for Social Studies Standards, compelling questions "deal with curiosities about how things work; interpretations and applications of disciplinary concepts; and unresolved problems that require students to construct arguments in response." They are important, based on application of knowledge, and debatable with more than one possible answer.

Compelling questions are imperative to drive inquiry and curiosity before students engage civically. But students need supporting questions which provide the subject matter scaffolding needed before students can develop and engage in compelling questions on climate change. What is climate? Why does climate change? These are examples of important supporting questions for students to explore before looking into compelling questions such as "How can we take action to mitigate climate change?"

\section{Standards}

Anchor.D.1 Collaboration: Work effectively with others with goal alignment.

DTC.B.1 Energy: Describe how the flow of energy drives the cycling of matter. DTC.D.1 Systems: Explain the multitude of systems Earth is composed of as well as the system Earth belongs to.

1.A Develop compelling questions that promote inquiry around key disciplinary concepts and embedded enduring issues

\section{Activities}

1. Learning Stations \#1 - Teacher introduces and answers three supporting questions: what is climate? What is energy? How is energy related to climate (Teacher Friendly Guide, pg. 38). Students then go to learning stations to learn how energy flows through Earth systems and affects the climate. They will create and evaluate comprehension "tests" (supporting questions) for other students.

(a) Air $=$ atmosphere, $($ TFG, pg. 28-29, 30)

(b) Water = hydrosphere, (TFG, pg. 28-29, 30)

(c) Ice $=$ cryosphere, (TFG, pg. 31-32)

(d) $\quad$ Land $=$ geosphere, (TFG, pg. 32-33)

(e) Life $=$ biosphere, $($ TFG, pg. 33) 
2. Learning Station $\# 2$ - Teacher introduces a compelling question: "To what extent is climate change caused by human activities?" Students then go to learning stations to learn about the different natural causes of climate change. They will create essay questions (compelling questions) and then evaluate other students' works.

(a) Plate tectonics (TFG, pg. 41-42, pg. 48)

(b) Earth's orbit around the sun, Milankovitch cycles (TFG, pg. 42, 44)

(c) Heinrich events (TFG, pg. 42)

(d) Younger Dryas, Little Ice Age, El Nino (TFG, pg. 43)

(e) Sun (solar flares, sunspots) (TFG, pg. 43)

\section{Unit 3: Challenges to Understanding Climate Change}

\section{Essential Questions}

- Why do we need systems thinking when addressing climate change?

- What are systems?

- How does systems thinking apply to climate change?

- How does human behavior influence climate change?

\section{Rationale}

Why is climate change so difficult to address? Understanding climate change involves learning about the complex interactions between multiple systems across disciplines. This is why it is imperative for students to develop skills in systems thinking, which is "a way of helping a person to view systems from a broad perspective that includes seeing overall structures, patterns and cycles in systems, rather than seeing only specific events in the system." As students develop their understanding of the ways interconnections between the elements of a system determine the behavior of the system, they can more effectively identify levers for systemic change. With systems thinking, students can turn their inquiry into some of the primary steps for taking informed action, identifying problems they might want to tackle when addressing climate change.

\section{Standards}

Anchor.B.1 Systems Thinking - Identify causal webs of external and internal factors.

0.A.1 Explain how life, including human life, influences and is influenced by the environment.

0.C.1 Interpret and create models and maps to understand (deep) time and scale of space.

1.B Craft meaningful and actionable problem statements through the lense of the affected human population based on analysis and synthesis of diverse relevant perspectives.

\section{Activities}

1. Create a System - After showing the concept of a system (https://www.youtube.com/watch? $\mathrm{v}=\mathrm{mNelPDgOcjs} \&$ list $=$ PLfhKSsmO71c0V50JIR7io 
SEOFdGuyNS3\&index=2, Climate Interactive, "The Whole System"), teacher introduces the carbon cycle system (TFG, pg. 47). Each group of students chooses one part of the carbon cycle system and maps out how it relates to other parts of the systems as well as outside of the system.

2. Iceberg Diagram - Teacher introduces the iceberg diagram (https://www.youtube.com/watch?v=MIIQ8Wfwu7c, Climate Interactive, "Iceberg Thinking Part 1"). Students read about the common causes of climate change (TFG, pg. 99-103). After, in small groups, students will choose an environmental issue from current events and ask "Why?" 5 times to create an iceberg diagram. Teacher asks students to identify areas of high leverage- the parts of a system that, when adjusted, will produce a significant change in the whole system.

3. Causal Diagrams - Teacher introduces causal diagrams through a video (https://www.youtube.com/watch?v=UgZTXf5PDis\&list=PLfhKSsmO71c 0V50JIR7io_SEOFdGuyNS3\&index=6\&t=0s, Climate Interactive, "Causal Diagrams"). In small groups, students refer back to their iceberg diagram and brainstorm one solution. Then, they create causal diagrams from their solution to summarize the effects of their solution.

\section{Unit 4: Defining Problems to Solve in the Context of Climate Change}

\section{Essential Questions}

- What are meaningful and actionable problem statements in the context of climate change?

- How is human life influenced by climate change?

- How do we identify root cause problems and areas of high leverage in climate change?

- How do we empathize to create actionable and meaningful problem statements?

\section{Rationale}

Defining a meaningful problem is the first step in policy analysis, design thinking, and conflict transformation. When understanding a problem, there's always a risk of jumping to a solution too quickly. Personal biases and blind spots about the causes of the problems can lead to false conclusions. That is precisely why it was so important to cultivate curiosity and build the skills of inquiry first.

There are also other challenges associated when creating problem statements specifically in the context of climate change due to psychological biases or political rhetoric. Ultimately, by applying the process of inquiry to assess real world problems associated with climate change in their region, students can begin to develop a collaborative project of their choice.

\section{Standards}

Anchor.A.1 Empathy: Communicate with people to understand why they do things, what their physical and emotional needs are, how they think about the world, and what is valuable to them. 
Anchar.C.2 Media Literacy: Metacognitively reflect on personal biases and blind spots.

0.A.1 1. Explain how life, including human life, influences and is influenced by the environment

1.B Craft meaningful and actionable problem statements through the lense of the affected human population based on analysis and synthesis of diverse, relevant perspectives

\section{Activities}

1. Carousel - In small groups, students find local problems related to climate change. Students map out the root causes using the iceberg diagram. Students rotate and debrief on what are common effects of climate change on everyday life.

2. Empathy Interviews - Using a common effect from the carousel activity, students identify an affected stakeholder. Teacher models how to conduct an empathy interview while students practice interviewing each other:

(a) Jobs and Tasks: What is this stakeholder trying to get done in their work or in their life?

(b) Pains: What annoys this stakeholder or prevents them from getting their jobs done?

(c) Gains: What are the outcomes or benefits that your stakeholder wants?

(d) For example: Jordanian residents are trying to use water for basic drinking needs, but water is too expensive. They want cheap and easy ways to access water.

3. Climate Change Leadership Project - Students begin "Step 1: Defining Problem" of their own project. While students identify stakeholders to interview, teacher should guide students:

(a) "Who would you specifically be interested to speak with regarding your topic?"

(b) "Write why you would be interested to speak with them, how they could inform your understanding of the problem, and how you assess their credibility on the specific topic?"

(c) "Compile questions that you would be interested to ask"

\section{Unit 5 Cognitive Biases and Logical Fallacies in Climate Change}

\section{Essential Questions}

- How do I limit the potential for cognitive biases and logical fallacies to influence my understanding of climate change?

- What are my own cognitive biases in the context of climate change?

- What are common logical fallacies in the context of climate change?

- How do I interpret and create models and maps to understand the scale of time and space in climate change? 


\section{Rationale}

With a defined problem statement, the next step is to gather evidence to understand the problem more holistically and to inform different ways of addressing the problem.

Before diving into research, it is important to understand your own cognitive biases and logical fallacies. Students should therefore learn what factors influence how they think to understand their knowledge gaps. A common bias is the availability heuristic, which is when we rely on immediate examples rather than information that is grounded in extensive data. Given the scale of time and space in climate change, students will learn how to interpret models and maps as one example of how to combat a cognitive bias.

\section{Standards}

Anchor.C.2 Media Literacy: Metacognitively reflect on personal biases and blind spots.

0.A.1 Explain how life, including human life, influences and is influenced by the environment

0.C.1 Interpret and create models and maps to understand (deep) time and scale of space.

1.A Determine the types of sources that will assist in understanding the problem and potential solutions.

\section{Activities}

1. Illustrating Biases - After reading about the "Factors that Influence How We Think" and cognitive biases in TFG (pg. 218-219), students journal about their own biases and blindspots that could undermine their understanding of climate change. The teacher then facilitates a discussion of strategies to minimize the impact of cognitive biases, including:

(a) Seeking feedback from diverse perspectives

(b) Separating ideas from individuals.

(c) Trying to focus less on existing processes, strategies, and technologies and envision new processes, strategies, and technologies.

(d) Being aware of your cognitive biases.

2. Fallacies - Teacher introduces common types of logical fallacies (https:// d32ogoqmya1dw8.cloudfront.net/files/integrate/teaching_materials/change_ inthe_air/what_logical_fallacies_pdf.v5.pdf). Student uses the internet to browse news articles or videos related to climate change and identify the specific logical fallacies.

3. Scales and Maps - Teacher shows how models that display patterns over time can help the understanding of climate change (https://www.bloomberg.com/ graphics/2015-whats-warming-the-world/). Students work in groups to identify different data points on an assigned climate change effect across time in any region to draw conclusions about the effects of climate change. Assigned effects can come from TFG (pg. 198-208): rising sea levels, heat waves, heavy rainfall, drought, extreme weather, reduced snowfall and snowpack. 


\section{Unit 6: Gathering Evidence from Credible Sources}

\section{Essential Questions}

- What is reliable evidence I can use to allow me to understand my problem and potential solutions in addressing climate change?

- What are the values and limitations of sources?

- How do I use qualitative data as evidence?

- What are existing mitigation strategies to address climate change?

\section{Rationale}

Before thinking of possible solutions to the problem statement students have chosen, they need to conduct research. This is a valuable skill, but with the technology and internet students have access to a wealth of information. As such, they need to develop the skills to navigate the resources at their disposal. Now, media literacy, which includes the ability to access, analyze, and evaluate sources is increasingly important.

Conducting research is hard, but students will need to learn this valuable skill in order to understand the problem better and to look at common solutions. Oftentimes, students do not have to reinvent the wheel, but rather evaluate the extent to which common solutions would work in their chosen context. Teaching students how to conduct interviews to obtain this information will not only excite students, but will also allow them to research context-driven solutions while cultivating an open mind to new and innovative solutions as well!

\section{Standards}

Anchor.C.2 Media Literacy: Critically analyze media in terms of origins, purpose, content, values, and limitations.

0.A.1 Explain how life, including human life, influences and is influenced by the environment

0.C.1 Interpret and create models and maps to understand (deep) time and scale of space.

1.A Gather relevant information from various and diverse sources and evaluate for credibility.

\section{Activities}

1. Values and Limitations of Sources - Teacher models how to annotate sources to analyze their credibility through a reading from Project Look Sharp's: Discourse or Disinformation Lesson Plan" (pg. 75-78).

(a) Origin: who, what, when, where publishing info, key details about origin.

(b) Purpose: Goal, informative/argumentative, intended audience

(c) Content: what is the summary of the source?

From the origin, purpose, and content, teacher discusses with the students what might be the value or limitation of the source. 
2. Collecting Data - Each group of students is assigned a mitigation strategy (TFG, pg. 152-175). They will produce a poster that summarizes the strategy as well as the pros and cons in the local context.
(a) Renewable Energy
(b) Nuclear Energy
(c) Energy Efficiency and Conservation
(d) Carbon Capture and Storage
(e) Land Use: Forests, Soils, and Agriculture
(f) Waste Management

3. Climate Change Leadership Project - Students begin "Step 2: Gathering Evidence" of their own project. While students identify stakeholders they want to interview, teachers should guide students in the similar fashion in Step 1:

- "Who would you specifically be interested to speak with regarding your topic?"

- "Write why you would be interested to speak with them, how they could inform your understanding of the problem, and how you assess their credibility on the specific topic"

- "Compile questions that you would be interested to ask"

\section{Unit 7: Brainstorming Strategies to Address Climate Change}

\section{Essential Questions}

- Based on my evidence, how do I creatively generate solutions to address climate change?

- What are mitigation and adaptation strategies to address climate change?

- How do I synthesize my evidence to develop relevant insights?

- How do I spark innovative ideas to address climate change?

\section{Rationale}

In addressing climate change, it is possible to analyze options in terms of mitigation and adaptation. Mitigation would involve using current technologies to address climate change by seeking to reverse the rate of increasing average global surface temperature (e.g. seeking to replace fossil fuels with renewable energy). In contrast, adaptation is focused on ways to minimize the impact of climate change that is happening and will continue into the future (e.g. new construction according to building codes designed to withstand flooding or other extreme weather related events that are likely to increase in frequency). Innovation is about developing new ways to address climate change with a focus on developing technologies and strategies that do not yet exist. Now that students have gathered background evidence, they will generate a broad range of ideas that can include different combinations of mitigation, adaptation, and innovation before using relevant criteria to narrow their choices in their context. 


\section{Standards}

Anchor.D.1 Collaboration: Work effectively with others through aligned goals. 0.A.1 Explain how life, including human life, influences and is influenced by the environment

3.A Synthesize evidence to generate a wide range of ideas to reach innovative solutions to a problem.

\section{Activities}

1. Adapting to Climate Hazards - Teacher presents adaptation strategies: relocate and retreat, adjust infrastructure, renew and conserve natural systems, make land use changes, modify management and operations, diversify to increase resilience, social innovation, risk management, and policy changes. Using TGF (pg. 198-208), students work in groups to come up with adaptation strategies for one of the described climate hazards. Students rotate and add different ideas for adaptation strategies to different posters.

2. Affinity Diagramming - Teacher presents a brainstorming strategy called affinity diagramming (https://www.youtube.com/watch?v=UynxDyr0lAo). Using the posters from the "Adapting to Climate Hazards" activity, students create a post-it note for each adaptation strategy. In groups, students group the post-its into themes and put headings onto these groups.

3. Attribute Listing - Teacher presents a strategy called attribute listening, where column headings are attributes.

\begin{tabular}{|l|l|l|l|l|}
\hline & Strategy & Incentive & Stakeholder & Medium \\
\hline Subsidize solar panels & Mitigation & Giving rewards & Households & Policy \\
\hline $\begin{array}{l}\text { Taxing businesses } \\
\text { based on carbon } \\
\text { consumption (carbon } \\
\text { taxes) }\end{array}$ & Mitigation & $\begin{array}{l}\text { Punishing bad } \\
\text { behavior }\end{array}$ & Businesses & Policy \\
\hline $\begin{array}{l}\text { Influence consumer } \\
\text { water conservation } \\
\text { behavior with the use } \\
\text { of smart meters and } \\
\text { pricing }\end{array}$ & Adaptation & $\begin{array}{l}\text { Increasing } \\
\text { awareness }\end{array}$ & Consumers & $\begin{array}{l}\text { App / } \\
\text { Technology }\end{array}$ \\
\hline $\begin{array}{l}\text { Foster community } \\
\text { networks that find and } \\
\text { help at-risk populations }\end{array}$ & Adaptation & Social Pressure & Communities & Social Networks \\
\hline
\end{tabular}


Teacher states that one strategy is to pick random attributes (such as the highlighted boxes in the table) and come up with new ideas. Students can also come up with new strategies, incentives, stakeholders, or medium.

4. Climate Change Leadership Project - Students begin "Step 3: Generating Solutions."

\section{Unit 8: Getting Feedback on Climate Change Strategies}

\section{Essential Questions}

- How do I receive honest feedback from local stakeholders on potential ways to address climate change?

- How do I create prototypes to communicate potential solutions?

- How do I test a hypothesis to receive meaningful and usable feedback from local stakeholders?

- What is geoengineering and how would local stakeholders be affected by this strategy?

\section{Rationale}

While students explore various solutions, it is better for them to engage with local stakeholders as a planning and implementation strategy for the solution they choose in addressing climate change. First of all, according to lean design thinking models, the earlier you get feedback, the less costly it is in both time and resources. Students should receive feedback on their potential solutions before they build on those solutions in the next step in which they draw conclusions with regard to the best path forward. Second of all, when local stakeholders are engaged, it creates possibilities to generate more targeted solutions and opens opportunities for stakeholders to be involved in the implementation of those solutions. Students will explore how to communicate with local stakeholders through creating simple prototypes. We will model how to do this while learning an innovative climate approach to addressing change- geoengineering.

\section{Standards}

Anchor.A.1 Empathy - Communicate with people to understand why they do things, what their physical and emotional needs are, how they think about the world, and what is valuable to them.

0.C.1 Interpret and create models and maps to understand (deep) time and scale of space.

0.D.1 Explain the multitude of systems Earth is composed of as well as the system Earth belongs to.

3.B Create externalized prototypes to communicate potential solutions and receive feedback.

\section{Activities}

1. Prototyping Pt. 1 - Teacher introduces geoengineering: "large-scale technological effort to change Earth's climate by removing carbon dioxide from the 
atmosphere or decreasing heat received from the sun." Teacher points out that it is easier to give feedback about a complicated solution through a visual. In small groups, students are assigned a geoengineering technique from TFG (pg. 182-189): enhanced chemical weathering, marine cloud brightening, stratospheric aerosol distribution, and surface albedo alteration. They must create a visual prototype of the process, present to the class, and receive feedback (pros and cons) of using the technique.

2. Prototyping Pt. 2 - Teacher presents a visual of ocean fertilization, a geoengineering solution (https://marinefoodchainsmn.tumblr.com/post/ 73374299312/solution-iron-fertilization). Students are divided into small groups and are assigned a stakeholder: politician, scientist, iron sulphate producers, fishermen and fisheries, community citizens (who use water). Students will come up with a list of questions to ask the stakeholder if they want to get feedback on ocean fertilization with the visual prototype.

3. Climate Change Leadership Project - Students continue "Step 3: Generating Solutions" of their own project.

\section{Unit 9: Creating Criteria for Effective Climate Change Solutions}

\section{Essential Questions}

- How do I create selection criteria for effective climate change solutions to the problem I am trying to address?

- What are common selection criteria to evaluate climate change solutions?

- How do I apply a cost-benefit analysis to climate change solutions?

- What are several systems and stakeholders to consider when evaluating climate change solutions?

\section{Rationale}

It is often very tempting to immediately choose a solution, but it is important to first systematically compare the different options. One of the strategies for students to use before drawing solutions for the best path forward is to identify selection criteria which are standards against which different solutions would be measured to see how they meet the goal of solving the problem. Students will work together to identify and prioritize selection criteria before narrowing down their solutions. Common selection criteria that we will explore include effectiveness and efficiency (cost-benefit analysis).

\section{Standards}

Anchor.B.1 Systems Thinking - Outline how actions can affect multiple stakeholders.

0.A.1 Explain how life, including human life, influences and is influenced by the environment.

4.B Identify selection criteria and apply the criteria to different prototypes of potential solutions 


\section{Activities}

1. Four Corners - Teachers will state an example of a mitigation, adaptation, and innovation strategy. Students will physically move to a corner in the classroom labelled as "Strongly Agree," "Agree," "Strongly Disagree," or "Disagree," reflecting their opinion of how effective the strategy is. Class discusses why they made their decision, leading them to develop selection criteria such as effectiveness, convenience, time, efficiency, sustainability, equity, feasibility, etc.

2. Cost-Benefit Analysis - Teacher explains the concepts of costs and benefits as well as strategies to use when conducting the analysis:

(a) Bottom up = one constructs detailed inventories of systems and their components in order to explore the relevant costs of specific adaptation methods.

(b) Top down = one uses aggregate data on a system and makes assumptions about the additional costs needed to apply adaptation techniques.

Students practice cost-benefit analysis from Box 9.2 Classroom exercise on cost-benefit assessment (TFG, pg. 198).

3. World Climate Simulation - "The World Climate Solution is a role playing exercise for groups in which participants engage in the UN climate change negotiations. It is unique in that it uses an interactive computer model to rapidly analyze the results of the mock-negotiations during the event." All directions, materials, and the program are available on this website: https://www. climateinteractive.org/programs/world-climate/

4. Climate Change Leadership Project - Students continue "Step 4: Drawing Conclusions" of their own project.

\section{Unit 10: Confronting Tradeoffs}

\section{Essential Questions}

- How do I systematically draw conclusions with regard to the best proposed solution to address climate change?

- How do I prioritize selection criteria?

- How do I project outcomes in the context of a proposed solution?

- How do I apply selection criteria to projected outcomes in order to assess the strengths and weaknesses of proposed solutions?

\section{Rationale}

The first instinct is to compare the different proposed solutions based on the selection criteria developed in the previous lesson. However, in order to evaluate solutions, we should be focusing on what the solutions would lead to. In other words, we need to look at the projected outcomes. Once the selection criteria are defined and the projected outcomes of alternative courses of action have been established, it is necessary to apply the criteria to the outcomes. With this infor- 
mation, it will be possible to compare the options systematically - an essential step towards deciding between them.

\section{Standards}

Anchor.B.1 Systems Thinking: Outline how actions can affect multiple stakeholders.

Anchor.B.2 Systems Thinking: Identify causal webs of external and internal factors within and between systems.

DTC.D.1 Earth Systems: Explain the multitude of systems Earth is composed of as well as the system Earth belongs to.

5.B Synthesize the assessment of the relative strengths and weaknesses of different outcomes to draw conclusions about how to proceed.

\section{Activities}

1. Values-based Reasoning - In small groups, students must identify whether a strategy that limits the availability of water in a region would be an effective strategy in addressing climate change. Teacher then facilitates a discussion of how values-based reasoning is essential to suggest that other than looking at criteria such as efficiency and effectiveness, what concerns of equity could arise from this type of solution? How could students bring in valued-based reasoning in a way that doesn't open the possibility of simply affirming a worldview because it is prevalent in society?

2. Modeling Projected Outcomes - Using Eugene Bardach's A Practical Guide for Policy Analysis, teacher explains what an outcomes matrix is (pg. 46-65). Teacher asks students to choose 3 policy alternatives to reduce carbon emissions and create an outcomes matrix in the similar fashion:

\begin{tabular}{l|l|l|l}
\hline & $\begin{array}{l}\text { Projected Outcome on } \\
\text { Selection Criteria \#1 }\end{array}$ & $\begin{array}{l}\text { Projected Outcome on } \\
\text { Selection Criteria \#2 }\end{array}$ & $\begin{array}{l}\text { Projected Outcome on } \\
\text { Selection Criteria \#3 }\end{array}$ \\
\hline$\# 1$ & & & \\
\hline
\end{tabular}

3. Climate Change Leadership Project - Students continue "Step 4: Drawing Conclusions" of their own project. Using Climate Generation, "Next Generation Climate for Grades 6-8" (https://curriculum.climategen.org/2017/ NGC/NGC2017-5-4-Worksheet-Claim-Evidence-Reasoning.pdf) teacher models how to create a claim, evidence, and reason from the outcomes matrix. Example:

(a) Claim: Requiring zero-energy capable homes is the best option for minimizing the impacts of climate change as a mitigation strategy.

(b) Evidence: The estimated cost to implement a plan would be around $\$ 132$ to $\$ 250$ per ton of carbon dioxide abated.

(c) Reasoning:

(i) Why does your evidence support your claim? 
1. Ex: This cost effectiveness was calculated based on....

(ii) Why is your evidence important? In other words, why is this selection criteria prioritized?

1. Ex: Cost effectiveness is important given the limited government budget of....

\section{Unit 11: Telling Your Story}

\section{Essential Questions}

- What are effective ways to communicate the results of this process to garner support for a potential solution for addressing climate change?

- How do I talk about controversial issues and complex systems?

- How do I develop empathy for various stakeholders?

- What are key questions to ask when creating media messages

\section{Rationale}

If someone were to ask about the problem being addressed and the solution you propose, how would you answer? It depends on the audience. Imagine someone like your grandmother.

Imagine other important target audiences. How would you advocate effectively for the course of action you propose? How might you engage with somebody who does not believe climate change exists? This analysis can lead to insight into overlooked stakeholders and/or interests that may be important to take into consideration. In general, it is important to think through everyone who would be involved in successful implementation in order to ensure that it is as effective as possible.

\section{Standards}

Anchor.A.2 Empathy - Engage in constructive dialogue connected to controversial issues, seeking to transform harmful dynamics and promote positive change. Anchor.D.1 Collaboration - Work effectively with others through aligned goals. DTC.B.1 Systems Thinking - Outline how actions can affect multiple stakeholders.

5.A Communicate the results of the process with relevant explanations and confront trade-offs.

\section{Activities}

1. Debate Role-Play - Teacher presents "Rules of Thumb for Teaching Controversial Issues" (TFG, pg. 214-215). Students then watch a debate between Bill Nye the Science Guy and Nick Loris of the Heritage Foundation regarding climate change, taking notes of effective and ineffective techniques of discourse. In small groups, students re-enact the debate with the new insights from class discussion. 
2. Teaching Others - Task students to teach another class the strategy they are proposing to address climate change. Before doing so, students should create an "Identity Chart" of the class they will be teaching for (Source: Facing History, https://www.facinghistory.org/resource-library/teaching-strategies/ identity-charts)

3. Creating Media - Teacher introduces different ways of using language and perspective in teaching climate change (TFG, pg. 223-230). Students will create a post on social media with a graphic illustration to communicate their proposal using the techniques they have just learned. Before creating their media message, they must answer "Key Questions to Ask When Creating Media Messages" from Project Look Sharp.

4. Climate Change Leadership Project - Students continue "Step 5: Communicating and Acting."

\section{Unit 12: Taking Action in Addressing Climate Change}

\section{Essential Questions}

- What direct actions can you take towards implementing the results of your analysis beyond telling your story?

- How do I create SMART goals?

- How do I make a project timeline?

- How do I take the first step?

\section{Rationale}

Once the course of action is selected and the underlying story/rationale can be conveyed clearly and powerfully, students are ready to plan their own individual action. Sometimes this involves asking about ways to support an ongoing local initiative. It can also take the form of a new initiative in the school or in the broader community. Their next step is to break it down into goals that are Specific, Measurable, Achievable, Relevant and Time-based (SMART goals). We hope that the students will be motivated and enabled to become effective climate change leaders within their communities!

\section{Standards}

Anchor.A.2 Empathy - Engage in constructive dialogue connected to controversial issues, seeking to transform harmful dynamics and promote positive change. Anchor.D.1 Collaboration - Work effectively with others through aligned goals. DTC.B.1 Systems Thinking - Outline how actions can affect multiple stakeholders.

5.B Take direct action towards implementing the results of the analysis.

\section{Activities}

1. SMART Goals - Using MindTools, "SMART Goals," teacher shows an example of a SMART goal and annotates it. In their small groups, students attempt to create a SMART goal for their proposed solution. Students will 
rotate and annotate the SMART characteristics in another group's SMART Goal.

2. Planning Projects - Using the Climate Change Connection's Youth Guide for Action, teacher walks through a project plan (https://climatechangeconnection.org/wp-content/uploads/2014/09/Climate_Guide_to_Action_en-1.pdf). After watching a video about Boyan Slat's Ocean Clean-up, students can practice outlining a project plan for Boyan.

3. Climate Change Leadership Project - Students finish "Step 5: Communicating and Acting." Teachers should have an assessment for students to present the culmination of their work to an authentic audience. Teachers should work with the school to determine how students can take the first steps in implementing their ideas to shift the learning from analysis to experience.

\section{Appendix B: Climate Change Leadership Project - Student Version}

This is a modified version of the student project guide. The full guide can be accessed: https://climatechangeleadership.weebly.com/

\section{Step 1: Defining Problems}

1. What is the problem I am trying to solve?

2. Root cause analysis: Why does this problem happen? Why? Why? Why? Why?

3. Stakeholder analysis: Who are the key stakeholders in the context of the chosen topic?

(a) Who is directly impacted?

(b) Who are local experts?

(c) Who is already seeking to affect change?

(d) Who else might be capable of affecting change?

4. Stakeholder profile map:

(a) Jobs and Tasks: What is this stakeholder trying to get done in their work or in their life?

(b) Pains: What annoys this stakeholder or prevents them from getting their jobs done?

(c) Gains: What are the outcomes or benefits that your stakeholder wants?

(d) Purpose, Credibility, Questions to ask

5. What is your problem statement now?

\section{Step 2: Gathering Evidence}

1. Record your sources using the following template 


\begin{tabular}{|l|l|l|}
\hline Origin & Purpose & Values and Limitations \\
\hline Who, What, When, Where & Goal: & \\
Publishing Info: & Informative/Argumentative: & \\
Key Details: & Intended Audience: & \\
& & \\
\hline
\end{tabular}

2. Plan your interview accordingly:

(a) Purpose of interview

(b) Information I know about the interviewee

(c) Possible Questions that are open ended, build on background information, draw out interesting ideas and information, and cover a range of relevant topics (adapted from The Critical Thinking Consortium).

\section{Step 3: Generating Solutions}

1. Synthesize your evidence by doing an affinity mapping exercise.

2. Individually brainstorm solutions.

3. Prototype your solution. Directions are adapted from Stanford d.school, "See Beyond: A Systems + Design Investigation" https://dschool.stanford.edu/ resources/seebeyond.

(a) What is the solution? How does it work? How does it solve your problem?

(b) Can you draw/visualize it here?

(c) Who/How to Implement? How does this solution get created and into the system? Who are local stakeholders?

\section{Interview Stakeholders}

(a) Identify the most relevant stakeholders.

(b) What is your goal? What do you want to find out from them?

(c) What are possible questions you might ask them for feedback.

\section{Step 4: Drawing Conclusions}

1. Selection criteria: What is your selection criteria? How important is this? Evidence

2. Outcomes Matrix

(a) What is your baseline?

(b) Create a matrix

\begin{tabular}{l|l|l|l}
\hline & Criteria \#1 & Criteria \#2 & Criteria \#3 \\
\hline Policy \#1 & & & \\
\hline Policy \#2 & & & \\
\hline
\end{tabular}


3. Conclusion

(a) Claim

(b) Evidence (Data)

(c) Reason

(i) Why does your evidence support your claim?

(ii) Why is your evidence important?

(d) Repeat b and c.

\section{Step 5: Communicating and Acting}

1. Identity chart: referencing your previous stakeholder charts, which one is the most important to communicate your proposed solution to? Highlight important aspects of their identity.

2. Media message: Before you create your own appealing media message, answer the following questions about your stakeholders. Source: Adapted from Project Look Sharp

(a) Authorship:

(i) Who am I representing in making this?

(ii) Who are my co-creators?

(b) Purpose:

(i) Why am I making this? Who is my target audience?

(ii) What do I want people to do as a result of my message?

(iii) What do I want people to think (or think about)?

(c) Economics

(i) Who might benefit from this message?

(ii) Who might be harmed by it?

(iii) Whose voices are represented or privileged? Omitted or silenced?

(iv) What is my responsibility to my audience?

(d) Content

(i) What messages and impressions do I want to convey?

(ii) What ideas, values, and information do I want to make explicit? Implied?

(iii) What will I choose to leave out of this message, and why?

(iv) Is my presentation of my information and ideas fair?

(e) Context:

(i) Where and how will I share this message with my audience?

(ii) How might cultural context influence the way people interpret my message? 
(f) Techniques:

(i) What techniques will work best to communicate the messages for this audience, and why?

(ii) Do I have (or need) permission to use this content?

(g) Interpretations:

(i) How (and why) might different people interpret this differently?

(ii) What do I learn about myself from my choices in making this?

(h) Responses:

(i) How might people feel after hearing, reading, or viewing this message?

(ii) What kinds of actions might people take in response to this?

3. Smart Goal:

(a) Specific: Who is involved? What do I specifically want to accomplish? Where? For what purpose?

(b) Measurable: How much? How many? What will I know when I have accomplished the goal?

(c) Achievable: How will I accomplish this goal? What are the obstacles or constraints to overcome?

(d) Relevant: How does the goal fit into the context of the area? How does it fit into your personal context?

(e) Time-based: What I can do in a year? What can I do in six months? What can I do in 2 weeks? What can I do today?

4. Project Implementation Plan (adapted from Climate Change Connections)

(a) List steps

\begin{tabular}{l|l|l|l|l}
\hline $\begin{array}{l}\text { Step } \\
\text { Number }\end{array}$ & $\begin{array}{l}\text { Steps Needed to } \\
\text { Achieve Your Goal }\end{array}$ & $\begin{array}{l}\text { How Will } \\
\text { You Do This }\end{array}$ & $\begin{array}{l}\text { What Help } \\
\text { Will I Need }\end{array}$ & $\begin{array}{l}\text { How will you know when } \\
\text { you are successful? }\end{array}$ \\
\hline
\end{tabular}

(b) What are possible challenges? How can you overcome this?

\section{References}

Al-Newashi, Q. (2002). Towards improving the status of the formal and nonformal environmental education in Jordan (Doctoral dissertation). Retrieved from Deutsche National Bibliothek. https://ediss.sub.uni-hamburg.de//volltexte/2002/696/

Andreou, N. (2020). Towards a generation of sustainability leaders: Eco-schools as a global green school movement for transformative education. In A. Gough, J. C.-K. Lee, \& E. P. K. Tsang (Eds.), Green schools globally: Stories of impact on education for sustainable development. Springer. (in press). 
Bardach, E. (2011). A practical guide for policy analysis: The eightfold path to more effective problem solving. Washington, DC: CQ Press.

Cairns, D. (2010). Investigating the relationship between instructional practices and science achievement in the inquiry-based learning. International Journal of Science Education, 41(15), 2113-2135. Retrieved from https://www.tandfonline.com/doi/full/10.1080/09500693.201 9.1660927.

Climate Interactive. (2019). Retrieved from https://www.climateinteractive.org/

Cohen, S. (2014). Understanding environmental policy. New York: Columbia University Press.

Cyprus Ministry of Education and Culture. (2012). SEMEP good practices first collection: Bridging cultures through science for sustainable environment.

Eames, C., \& Mardon, H. (2020). The enviroschools programme in Aotearoa New Zealand: Actionorientated, culturally responsive, holistic learning. In A. Gough, J. C.-K. Lee, \& E. P. K. Tsang (Eds.), Green schools globally: Stories of impact on education for sustainable development. Springer. (in press).

EcoPeace Middle East. (2019). Climate change, water security, and national security for Jordan, Palestine, and Israel.

Gonzalez-Gaudiano, E., \& Meira-Cartea, P. (2012). Climate change education and communication: A critical perspective on obstacles and resistances. In Education and climate change (1st ed., pp. 13-34). New York: Routledge.

Haber, T. L. (2019). Environmental leadership seminar. Israel: Arava Institute.

Intergovernmental Panel on Climate Change. (2018). Special report on global warming of $1.5^{\circ} \mathrm{C}$. Retrieved from https://report.ipcc.ch/sr15/pdf/sr15_spm_final.pdf

Intergovernmental Panel on Climate Change. (2019a). Climate change and land. Retrieved from https://www.ipcc.ch/site/assets/uploads/2019/08/Edited-SPM_Approved_Microsite_FINAL.pdf

Intergovernmental Panel on Climate Change. (2019b). The ocean and cryosphere in a changing climate. Retrieved from https://report.ipcc.ch/srocc/pdf/SROCC_FinalDraft_FullReport.pdf

Karama, M. (2016). A comparative survey of environmental education goals between UNESCO framework and 10th grade Palestine curriculum. International Journal of Curriculum and Instruction, 8(2), 1-17. Retrieved from https://files.eric.ed.gov/fulltext/EJ1207324.pdf.

Ledley, T. S., Rooney-Varga, J., \& Niepold, F. (2017). Addressing climate change through education. Oxford Research Encyclopedia of Environmental Science. https://doi.org/10.1093/ acrefore/9780199389414.013.56.

National Council for Social Studies. (2017). College, Career \& Civic Life C3 Framework for Social Studies State Standards: Guidance for Enhancing the Rigor of K-12 Civics, Economics, Geography, and History. Retrieved from https://www.socialstudies.org/sites/default/files/2017/ Jun/c3-framework-for-social-studies-rev0617.pdf

Next Generation Science Standards. (2019, September 9). Retrieved from https://www.nextgenscience.org/

Platner, H. (n.d.). An introduction to design thinking: Process guide. An introduction to design thinking: PROCESS GUIDE. Stanford: Institute of Design at Stanford. Retrieved from https:// s3-eu-west-1.amazonaws.com/ih-materials/uploads/Introduction-to-design-thinking.pdf.

Project Look Sharp: K-12 \& Higher Ed. Media Literacy Lesson Plans: Ithaca College. (n.d.). Retrieved from https://www.projectlooksharp.org/

Reimers, F. (2020). Educating global citizens. Springer.

Sagy, G., \& Tal, A. (2015). Greening the curriculum: Current trends in environmental education in Israel's public schools. Israel Studies, 20(1), 57-85. Retrieved from https://www.jstor.org/ stable/10.2979/israelstudies.20.1.57?seq=1.

Selby, D., \& Kagawa, F. (2013). Climate change in the classroom: UNESCO course for secondary teachers on climate change education for sustainable development. UNESCO.

Tal, T. (2020). Green schools in Israel: Multiple rationales and multiple action plans. In A. Gough, J. C.-K. Lee, \& E. P. K. Tsang (Eds.), Green schools globally: Stories of impact on education for sustainable development. Springer. (in press).

UN CC: Learn. (2013). Integrating climate change in education at primary and secondary level. Integrating climate change in education at primary and secondary level. Retrieved from 
https://www.uncclearn.org/sites/default/files/resource_guide_on_integrating_cc_in_education_primary_and_secondary_level.pdf

UNESCO \& United Nations Environment Programme. (2011). YouthXchange guidebook series: climate change and lifestyles. Retrieved December 11, 2019 from https://unesdoc.unesco.org/ ark:/48223/pf0000212876

UNESCO Associated Schools Network. (n.d.). Retrieved from https://aspnet.unesco.org/en-us/ climate-education-education

UNESCO GAP Priority Action Areas. (2019, March 4). Retrieved October 3, 2019, from https:// en.unesco.org/gap/priority-action-areas

UNESCO Institute of Statistics. (2020). Retrieved February 25, 2020, from http://uis.unesco.org/

United Nations. (2015). Transforming our world: The 2030 agenda for sustainable development. Transforming our world: The 2030 agenda for sustainable development. Retrieved from https://sustainabledevelopment.un.org/content/documents/21252030+Agenda+for+Sustainabl e+Development+web.pdf

United Nations Climate Change - Summit 2019. (n.d.). Retrieved October 3, 2019, from https:// www.un.org/en/climatechange/education-key-climate-change.shtml

Zabel, I. H. H., Duggan-Haas, D., \& Ross, R. M. (2017). The teacher-friendly guide to climate change. Ithaca: Paleontological Research Institution.

David Rhodes taught English in Nicaragua, and he taught history, philosophy, and English in Colombia. Then he began teaching social studies, Spanish, and service learning at the middle school level in Corning, New York. In addition to classroom instruction, David also facilitated leadership development programs, and he coordinated professional learning workshops related to civic education and media literacy. He is a graduate of the Education Policy and Management Masters program at the Harvard Graduate School of Education. David is passionate about fostering thoughtful civic leaders and creating opportunities for students to collaborate on meaningful projects as they engage in learning that transcends the walls of the classroom.

Margaret Wang was a secondary educator in social studies, economics, business management, and entrepreneurship in an international school in Bahrain. She has also taught English and Public Speaking in several regions in China and Japan. She is a graduate of the International Education Policy Masters program at the Harvard Graduate School of Education. She loves to empower students to realize their potential and become agents of social change.

Open Access This chapter is licensed under the terms of the Creative Commons Attribution 4.0 International License (http://creativecommons.org/licenses/by/4.0/), which permits use, sharing, adaptation, distribution and reproduction in any medium or format, as long as you give appropriate credit to the original author(s) and the source, provide a link to the Creative Commons license and indicate if changes were made.

The images or other third party material in this chapter are included in the chapter's Creative Commons license, unless indicated otherwise in a credit line to the material. If material is not included in the chapter's Creative Commons license and your intended use is not permitted by statutory regulation or exceeds the permitted use, you will need to obtain permission directly from the copyright holder.

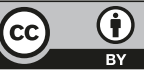

